\title{
Ideologia partidária e crise fiscal dos estados: o caso de Minas Gerais
}

\author{
Party ideology and the fiscal crisis of Brazilian States: notes on Minas Gerais
}

\author{
Lúcio Otávio Seixas Barbosa (1) \\ Raimundo de Sousa Leal Filho(2) \\ Francisco Alves de Oliveira Junior ${ }^{(3)}$ \\ Felipe Magno Parreiras de Sousa ${ }^{(4)}$
}

\author{
(1) Fundação João Pinheiro \\ (2) Fundação João Pinheiro \\ ${ }^{(3)}$ Controladoria-Geral do Estado de Minas \\ Gerais \\ (4) Secretaria de Estado de Planejamento e \\ Gestão
}

\begin{abstract}
This papers aims at investigating the nexus between party ideology and public expenditures in the state of Minas Gerais (Brazil). Particularly, we assess if the current fiscal deficit deterioration has to do with the take over of a left-wing party in the state since 2015. To this end, we compare revenue and expenses dynamics, focusing on the results of the last four years, when a left-wing political party (PT) replaced a more centre one (PSDB). The results show that the PT government tried to adjust the public accounts, albeit unsuccessfully.
\end{abstract}

\section{Keywords}

party ideology, fiscal crisis of Brazilian states, Minas Gerais.

JEL Codes H720, H300.

\section{Resumo}

O presente estudo investiga a relação entre ideologia partidária e os gastos públicos no estado de Minas Gerais. Em particular, avalia-se se a deterioração fiscal do estado no quadriênio 2015 2018 se relaciona, em alguma medida, à mudança de orientação partidária no governo mineiro. Compara-se, então, a dinâmica das receitas e dos gastos estaduais nos últimos dezesseis anos, destacando os resultados da última gestão, quando houve a mudança de governo e de ideologia partidária. Os resultados mostram que o governo do Partido dos Trabalhadores (PT), embora mais à esquerda do espectro político, se esforçou para ajustar as contas públicas, ainda que sem sucesso.

\section{Palavras-chave}

ideologia partidária, crise fiscal dos estados, Minas Gerais.

Códigos JEL H720, H300. 


\section{Introdução}

A crise econômica brasileira recente se desdobrou na crise fiscal dos estados brasileiros. Em maior ou menor grau, as 27 unidades da federação enfrentam escassez de recursos para investimento, regimes previdenciários deficitários e dificuldades com o pagamento de dívidas. $O$ caso mineiro é o retrato desse fenômeno. $O$ crescimento das receitas se retraiu fortemente no último quadriênio (2015-2018), apesar do empenho do governo para aumentar a arrecadação. Por outro lado, as despesas continuaram crescendo acima da inflação, a despeito da tentativa de se conter os gastos públicos, em especial via investimentos. O resultado dessa equação foi o surgimento de déficits crescentes, dificuldade de honrar compromissos, atrasos de pagamento do servidor etc.

O fato de a crise das finanças públicas estaduais ser praticamente generalizada sugere que os entes subnacionais partilham de problemas relativamente similares. Os esforços dos governos estaduais para expandir a arrecadação (e.g., majoração de alíquotas de impostos e da contribuição previdenciária) se mostram insuficientes frente a) à lenta retomada da economia e b) à rigidez e ampliação dos gastos com ativos e inativos (IPEA, 2018).

No entanto, a crise econômica não afetou todas as unidades de forma idêntica. Em geral, nos estados com maior participação da indústria de transformação (Minas Gerais, São Paulo e Rio Grande do Sul), a duração e a magnitude da crise foram superiores (Colombo; Lazzari, 2018). Em Minas Gerais, a estrutura produtiva da economia é caracterizada pelo forte peso da cadeia de produção dos insumos da metal-mecânica, vinculando-se como fornecedora para o núcleo industrial centrado em São Paulo e no Rio de Janeiro. Dessa forma, ela é extremamente vulnerável às flutuações do ciclo econômico comandadas pela formação de capital nas atividades da indústria de transformação e na indústria da construção.

De acordo com Fundação João Pinheiro (2018), 32,9\% de todo o Valor Bruto da Produção realizado no estado em 2010 teve origem nas empresas cuja atividade principal envolvia algum segmento da indústria de transformação. Mesmo com a intensidade da retração econômica no biênio 2015-2016, estas ainda responderam por 28,1\% daquele total no "fundo do poço" atingido em 2016.

Leal Filho e Barbosa (2018) estimaram, com base no desempenho da economia de Minas Gerais durante o período 1995-2014, uma taxa de cres- 
cimento tendencial de apenas $2,2 \%$ ao ano para o PIB estadual (contra $2,6 \%$ ao ano para o Brasil). Dado o comportamento efetivamente observado durante a recessão de 2014-2016, com retração do índice de volume do PIB de Minas por três anos consecutivos e fraquíssima recuperação em 2017, eles calcularam que $\mathrm{R} \$ 177,9$ bilhões (ou 10,3\% de todo o PIB estadual acumulado no triênio 2015-17) deixaram de ser gerados, com um correspondente impacto na frustração de receitas para os governos estadual e municipais.

Adicionalmente, a resiliência das finanças públicas estaduais à crise também não foi igual. Em primeiro lugar, porque existem diferenças nos gastos com pessoal ativo e inativo e, também, no déficit previdenciário. Em Minas Gerais, o déficit da previdência é relativamente mais elevado do que o observado nos demais estados do Sudeste. E, em segundo lugar, porque a composição de gastos de cada estado no período anterior (2010 a 2014) era distinta. O estado de São Paulo, diante do aumento da receita nesse período, optou por aumentar os investimentos com recursos próprios. O Rio de Janeiro, por outro lado, escolheu financiar seus investimentos via operações de crédito (Minas Gerais se enquadra nessa categoria). Dessa forma, o espaço fiscal do primeiro era maior, permitindo o ajuste das contas via redução de investimentos no momento da crise (IPEA, 2018; IFI, 2018).

Em Minas Gerais, coincidentemente, a deterioração fiscal foi marcada pela mudança de governos. De 2003 a 2014, o estado foi governado por representantes do Partido da Social Democracia Brasileira (PSDB). Foram dois governos do Aécio Neves (2003-2006 e 2007-2010) e o outro do Antônio Anastasia e Alberto Pinto Coelho ${ }^{1}$ (2011-2014). De 2015 em diante, o Partido dos Trabalhadores (PT), representado por Fernando Pimentel, assumiu a gestão do estado.

De acordo com a literatura, embora os resultados não sejam conclusivos, governos estaduais com orientação de esquerda seriam favoráveis a políticas fiscais expansionistas. Nesse caso, os resultados das contas públicas seriam, naturalmente, piores na gestão do governo Pimentel, cuja ideologia se aproxima mais da esquerda. ${ }^{2}$

1 Alberto Pinto Coelho era o vice-governador, assumindo em 2014, último ano do mandato, quando Anastasia se afastou para se candidatar ao Senado.

2 A classificação da orientação partidária de um partido não é tarefa simples (ver Arvate; Avelino; Lucinda, 2010). Assume-se aqui que a ideologia partidária do PT é mais à esquerda 
Por outro lado, as mudanças institucionais implementadas ao longo da década de 1990 e dos anos 2000, em particular a Lei de Responsabilidade Fiscal (LRF), restringiram o grau de liberdade dos governos estaduais em realizar gastos e financiar déficits (Cossio, 2001; Botelho, 2002; Nakaguma; Bender, 2006). Adicionalmente, no contexto atual de crise econômica e fiscal, assume-se que a margem de manobra dos estados seja ainda mais reduzida. Portanto, supõe-se que, no quadriênio 2015-2018, os governos estaduais, sejam de esquerda ou de direita, estiveram empenhados em ajustar as contas públicas, em virtude de restrições legais e da crise financeira.

O presente artigo visa justamente a avaliar o esforço fiscal da gestão petista em perspectiva histórica. Ou seja, compara-se a trajetória recente das receitas e despesas ao seu comportamento em ciclos quadrienais anteriores, quando a orientação do governo era mais próxima do centro (PSDB). Além disso, investiga-se a composição estrutural de ambas. Dessa forma, pondera-se o impacto de questões conjunturais e estruturais sobre as finanças públicas estaduais. ${ }^{3}$

Na próxima seção, discute-se a questão da influência ideológico-partidária nos resultados orçamentários dos governos. Em seguida, traça-se um breve panorama da situação fiscal de Minas Gerais e examina-se a dinâmica da receita e da despesa orçamentária, com enfoque no período de 2015 a 2018. Ao final, são apresentadas as conclusões dessa análise.

\section{Ideologia partidária, restrições legais e resultados orçamentários}

A literatura que discute a possibilidade de fatores políticos afetarem o comportamento das variáveis econômicas se divide, basicamente, em duas linhas: ciclos políticos oportunistas e ciclos partidários.

$\mathrm{Na}$ primeira vertente, os policymakers, independentemente da orientação ideológica, visam fundamentalmente manterem-se no poder. Um mandatário oportunista estimularia a demanda agregada no ano eleitoral, aumentando o emprego ao custo de uma inflação mais alta no período

3 A maior parte dos dados apresentados no artigo foi obtida no Armazém-SIAFI do estado de Minas Gerais. No entanto, eles também podem ser consultados no portal da transparência do governo. 
subsequente (Nordhaus, 1975). Essa hipótese, do ponto de vista teórico, se sustenta quando as expectativas sobre a inflação não são racionais (forward-looking).

A partir da revolução das expectativas racionais, nos anos de 1970, surgiu a vertente de ciclos políticos orçamentários, na qual ganha destaque a assimetria de informação entre o eleitor e o mandatário. Nessa linha, além de manipulações da política monetária com vistas a aumentar o emprego, os governantes manejam o orçamento para sinalizar competência aos eleitores. Promovem, então, expansões fiscais nos anos eleitorais, direcionando os gastos para bens e serviços, cuja provisão governamental é imediata e visível, ${ }^{4}$ a fim de se reelegerem (ou eleger o candidato de sua preferência) (Brender; Drazen, 2005).

Do ponto de vista empírico, os modelos que preveem a manipulação do orçamento apresentam melhores resultados do que os que sugerem a manipulação de variáveis macroeconômicas (Alesina; Roubini; Cohen, 1997). Desse modo, a literatura atual tem se desenvolvido nessa direção (ciclos políticos orçamentários).

Na segunda abordagem - ciclos partidários - destaca-se a influência de diferenças ideológicas e, mais explicitamente, partidárias, sobre o comportamento da economia. Partidos de esquerda tenderiam a favorecer um Estado maior e mais ativo, valendo-se de instrumentos fiscais para restringir as desigualdades causadas pelo funcionamento da economia de mercado. De outro lado, partidos de direita estariam mais preocupados com a manutenção da estabilidade da economia e em assegurar o livre funcionamento do mercado. Assim, seriam caracterizados por um Estado menor e menos ativo. Mais especificamente, os primeiros se concentrariam no combate ao desemprego, e o segundo no controle da inflação (Hibbs, 1977). Em linhas gerais, seria razoável esperar que a despesa seja maior em governos de esquerda (resultados orçamentários piores e maior peso do governo na economia).

Esse modelo foi também adaptado para um contexto de expectativas racionais (Alesina; Roubini, 1990). Os eleitores, com base em suas preferências, votam no partido que maximiza sua utilidade esperada. Escolhem, então, entre partidos de esquerda (combate ao desemprego) e partidos de direita (controle da inflação).

4 O caso clássico de sinalização de competência seria a inauguração de obras às vésperas da eleição. 
Essas duas linhas teóricas - ciclos políticos orçamentários e ciclos partidários - não são incompatíveis. Políticos partidários podem simultaneamente adotar políticas monetárias e fiscais conforme as preferências ideológicas e, à medida que a eleição se aproxima, optarem por condutas oportunistas. Haveria um trade-off entre maximizar os votos e seguir a ideologia partidária. A necessidade de se manter o apoio das bases sociais e a dificuldade de se atrair votos do centro político impediriam que a conduta do político (ou partido) fosse apenas oportunista. $O$ resultado da combinação desses dois modelos é conhecido como ciclo político situacional (Queiroz; Silva, 2010).

Em termos empíricos, diversos estudos atestam a existência de ciclos políticos orçamentários em diferentes níveis de governo (local ou nacional) e em diferentes países. ${ }^{5}$ Em relação aos ciclos partidários, a literatura internacional e os estudos para o Brasil tendem a refutar sua validade.

Destaca-se que alguns estudos avaliam a relação entre a ideologia partidária e o "tamanho" do governo (medido através dos gastos públicos), e outros analisam a influência da ideologia na composição dos gastos. No primeiro caso, os resultados da literatura internacional não são consensuais e sugerem que diferenças ideológicas não influenciam de modo sistemático os indicadores fiscais nem no nível federal nem no local (Potrake, 2011a). No segundo, as evidências também não são conclusivas, mas indicam que existem diferenças de prioridade de gastos nos governos de esquerda (grosso modo, priorizam a redistribuição de renda via gastos sociais) (Connoly; Mason, 2016; Dasha; Raja, 2012; Potrake, 2011b, entre outros).

No entanto, Potrake (2011a) pondera que a ideologia partidária tem influência apenas marginal tanto na composição dos gastos quanto nos resultados orçamentários. A partir da análise dos países da Organização para a Cooperação e Desenvolvimento Econômico (OCDE), de 1997 a 2007, o autor conclui que nas últimas décadas a ideologia partidária influenciou, sobretudo, questões não orçamentárias (alinhamento político aos Estados Unidos, por exemplo).

Esse resultado vale também para o processo de consolidação fiscal dos países europeus após a crise econômica de 2008. Segundo Kickert et al. (2015), a profundidade das medidas de consolidação fiscal derivou da restrição de fatores econômicos e supranacionais e não necessariamente de faentre outros. Para comparações entre países, ver Schuknecht (2000) e Shi e Svensson (2006). 
tores políticos domésticos. Em geral, as medidas de ajustes foram similares (congelamento de contratações e de salários, redução de salários, demissões etc.), e cortes drásticos no orçamento foram a exceção e não a regra.

No Brasil, os estudos sobre a influência da ideologia nos resultados orçamentários e na composição do gasto também não são conclusivos. Avaliando os governos estaduais, Cossio (2001) assinala que os governos de esquerda tendem a utilizar políticas fiscais mais expansivas. Nakaguma e Bender (2006) sugerem que eles priorizam gastos com educação (resultado similar ao de Bittencourt e Hilbrecht, 2003). Entretanto, de modo geral, os resultados são frágeis e uma das explicações seria o fato de as estruturas partidárias serem voláteis e com ideologias instáveis. Logo, não se pode afirmar nem que os resultados orçamentários de governos de esquerda são piores do que os de direita nem que há diferenças na composição de gastos.

Nesse debate, é fundamental levar em consideração as mudanças institucionais implementadas no Brasil nos anos de 1990 e 2000, sobretudo após a implementação da Lei de Responsabilidade Fiscal (LRF). À época da implantação do Plano Real, os governadores, hesitantes em face dos problemas relacionados à dívida pública e aos bancos estaduais, perderam o controle das contas públicas. A partir de então, através do programa de ajuste fiscal, o governo federal passou a ditar as regras de gastos dos entes federados. A LRF completou a mudança do aparato institucional, estabelecendo limites legais para a dívida consolidada, operações de crédito e gastos com pessoal (Lopreato, 2008).

Inclusive, no período dessas mudanças (entre os anos de 1995 e 2005), os resultados orçamentários dos estados, ${ }^{6}$ independentemente da posição ideológica do governo, mostraram significativa melhora (Arvate; Avelino; Lucinda, 2008). No entanto, na atual crise fiscal, fica patente que nem o programa de ajuste fiscal nem a LRF foram instrumentos suficientes para impedir a deterioração das finanças públicas dos estados.

$\mathrm{Na}$ verdade, a agenda fiscal, preocupada exclusivamente com a questão do ajuste das contas públicas estaduais, contribuiu para debilitar a posição estadual na ordem federativa. A discussão sobre o federalismo brasileiro ${ }^{7}$ e, em particular, do papel dos estados nesse arranjo, foi negligenciada e substituída pela imposição de regras fiscais. $O$ resultado é estados frágeis

6 Para um estudo sobre Minas Gerais, ver Jayme Jr., Reis e Romero (2007).

7 Para uma discussão sobre a teoria do federalismo fiscal, ver Silva (2005). 
tanto no aspecto financeiro quanto na capacidade de articulação de políticas públicas consequentes.

Adicionalmente, a rigidez orçamentária (principalmente, despesas com pessoal) contribuiu negativamente na capacidade de os governos estaduais administrarem o orçamento (Chevitarese, 2009). Em situações de crise econômica, tal qual a vivenciada pelos estados brasileiros entre 2014 e 2016, os resultados da combinação de rigidez de gastos e queda de receita são déficits orçamentários.

Se em 2008 Lopreato (2008) alertava sobre a insustentabilidade, no longo prazo, dos gastos estaduais com despesa de pessoal (ativos e inativos), na atual conjuntura essa questão tem contribuído significativamente para a crise financeira dos estados. Em parte, os governos respondem a partir de métodos de contabilidade criativa (Oliveira, 2010), reclassificando despesas de pessoal em outras rubricas. Entretanto, essa alternativa apenas mascara o problema. E, num contexto em que os déficits atuariais dos regimes de previdência do servidor Público (RPPS) se avolumam, é, claramente, insuficiente para superá-la.

Nesse cenário, do ponto de vista teórico, a possibilidade de se identificar a ocorrência de ciclos partidários nas finanças públicas estaduais em períodos de crise é baixa. Os governantes não têm margem de manobra, de modo que, independentemente da orientação ideológica, buscam reduzir gastos discricionários e aumentar receitas.

Portanto, o presente estudo busca corroborar essa hipótese, aferindo se houve a presença de viés ideológico na condução da política fiscal, entre 2015 e 2018, na gestão petista em Minas Gerais. Adicionalmente, avalia se as administrações anteriores do PSDB foram mais responsáveis do ponto de vista fiscal. A análise se concentra na dinâmica das despesas e receitas, com ênfase na análise das categorias econômicas da receita e da despesa. Na seção seguinte, traça-se um breve panorama da situação fiscal do estado no período da petista.

\section{Panorama fiscal do estado de Minas Gerais}

Desde o início da recessão econômica em $2014,{ }^{8}$ o estado de Minas Gerais tem apresentado sucessivos déficits fiscais. A Tabela 1 apresenta os resul8 De acordo com o comitê de Datação de Ciclos Econômicos (CODACE), a recessão econômica brasileira durou 11 trimestres - entre o segundo trimestre de 2014 e o quarto trimestre de 2016. 
tados orçamentário, ${ }^{9}$ comparando as receitas efetivadas com as despesas realizada, ${ }^{10}$ e primário do estado. Em 2018, o valor nominal do déficit foi superior a 10 bilhões, ou seja, superior a 10\% do valor arrecadado.

Tabela 1 Resultado da execução orçamentária e primário - Minas Gerais - 2002-2018 - (em milhões $\mathrm{R} \$ 1,00)$

\begin{tabular}{lrrrrr}
\hline Ano & Receitas & Despesas & $\begin{array}{r}\text { Superávit/ } \\
\text { Déficit }\end{array}$ & $\begin{array}{r}\text { Superávit/ } \\
\text { Déficit Primário }\end{array}$ \\
\hline 2002 & $18.521,30$ & $19.359,44$ & $(838,14)$ & 488,81 \\
\hline $\mathbf{2 0 0 3}$ & $19.914,46$ & $20.263,46$ & $(348,99)$ & 991,39 \\
\hline $\mathbf{2 0 0 4}$ & $21.817,26$ & $21.726,61$ & 90,65 & $1.523,27$ \\
\hline $\mathbf{2 0 0 5}$ & $25.513,72$ & $25.292,07$ & 221,65 & $1.928,25$ \\
\hline $\mathbf{2 0 0 6}$ & $29.099,92$ & $29.018,79$ & 81,13 & $1.937,27$ \\
\hline $\mathbf{2 0 0 8}$ & $32.633,25$ & $32.443,15$ & 190,10 & $2.308,78$ \\
\hline $\mathbf{2 0 0 9}$ & $39.923,33$ & $39.299,36$ & 623,97 & $2.971,29$ \\
\hline $\mathbf{2 0 1 0}$ & $40.562,70$ & $40.263,46$ & 299,24 & $1.732,67$ \\
\hline $\mathbf{2 0 1 1}$ & $46.617,95$ & $46.051,17$ & 566,78 & $1.851,10$ \\
\hline $\mathbf{2 0 1 2}$ & $54.844,45$ & $54.693,57$ & 150,89 & $2.756,66$ \\
\hline $\mathbf{2 0 1 3}$ & $65.248,61$ & $63.172,17$ & $2.076,44$ & $3.068,53$ \\
\hline $\mathbf{2 0 1 4}$ & $70.958,45$ & $71.906,53$ & $(948,08)$ & $(86,16)$ \\
\hline $\mathbf{2 0 1 5}$ & $73.347,44$ & $75.512,92$ & $(2.165,49)$ & $1.030,99$ \\
\hline $\mathbf{2 0 1 6}$ & $76.154,85$ & $85.119,04$ & $(8.964,18)$ & $(3.243,58)$ \\
\hline $\mathbf{2 0 1 7}$ & $83.965,71$ & $88.129,10$ & $(4.163,39)$ & $(3.249,13)$ \\
\hline $\mathbf{2 0 1 8}$ & $88.623,91$ & $98.391,67$ & $(9.767,76)$ & $(6.123,57)$ \\
\hline & $91.753,96$ & $102.986,64$ & $(11.232,68)$ & $(4.119,16)$ \\
\hline
\end{tabular}

Fonte: Elaboração própria a partir de dados do Sistema Integrado de Administração Financeira de Minas Gerais (Siafi-MG).

Nota: A partir do exercício de 2018, a apuração do resultado primário, divulgada no Relatório Resumido da Execução Orçamentária (RREO), passou a desconsiderar as operações intraorçamentárias. Na tabela 1, para consistência da série temporal, os valores apresentados para todos os anos possuem os valores das operações intraorçamentárias.

9 A Portaria STN n 328, de 27/08/2001, estabeleceu para os Estados, Distrito Federal e Municípios novos procedimentos contábeis para registro dos recursos destinados e oriundos do Fundo de Manutenção do Ensino Fundamental e Valorização do Magistério (FUNDEF). Essas mudanças foram adotadas em Minas Gerais a partir de 2004. Portanto, os valores de 2002 e 2003 da Tabela 1 são diferentes do relatório contábil da Secretaria de Fazenda.

10 A receita efetivada corresponde ao ingresso das receitas nos cofres públicos. A despesa realizada é igual à despesa liquidada ao longo do ano e à despesa empenhada no encerramento do exercício. 
Observa-se, nos últimos anos, o descasamento entre receita e despesa. A série de déficits orçamentários se inicia em 2013, na gestão do governador Antônio Anastasia, embora em 2014 não tenha sido registrado déficit primário. Logo, a despeito da orientação partidária, havia indícios da existência de problemas estruturais nas finanças públicas. Nos anos subsequentes, já na gestão petista, há nítida deterioração fiscal.

Tabela 2 Principais indicadores da LRF - Minas Gerais - 2003-2018 - (\%)

\begin{tabular}{lr|r}
\hline Ano & $\begin{array}{r}\text { Pessoal/ } \\
\text { Receita Corrente Líquida }\end{array}$ & $\begin{array}{r}\text { Dívida Consolidada Líquida/ } \\
\text { Receita Corrente Líquida }\end{array}$ \\
\hline 2003 & $\ldots$ & 243 \\
\hline 2004 & 48,33 & 224 \\
\hline 2005 & 43,49 & 203 \\
\hline 2006 & 44,58 & 189 \\
\hline 2007 & 46,37 & 188 \\
\hline 2008 & 45,76 & 176 \\
\hline 2010 & 46,16 & 179 \\
\hline 2011 & 48,61 & 182 \\
\hline 2012 & 38,85 & 182 \\
\hline 2013 & 40,73 & 174 \\
\hline 2014 & 41,49 & 183 \\
\hline 2015 & 43,49 & 178 \\
\hline 2016 & 47,91 & 198 \\
\hline 2017 & 49,29 & 203 \\
\hline 2018 & 49,99 & 186 \\
\hline & 66,65 & 189 \\
\hline
\end{tabular}

Fonte: Secretaria de Estado da Fazenda de Minas Gerais, Relatório de Gestão Fiscal terceiro quadrimestre.

Aliado aos recorrentes déficits houve piora em indicadores-chaves da LRF. A relação entre gastos com pessoal e receita corrente líquida, no poder Executivo, ultrapassou o limite de $50 \%$ permitido pela legislação. ${ }^{11}$

11 Entre 2010 e 2011, houve uma queda de aproximadamente 10 pontos percentuais na razão despesas com pessoal/Receita Corrente Líquida (RCL). Essa mudança brusca se relaciona a criação de um novo item de despesa, classificado no grupo de despesa "outras despesas correntes", qual seja: aporte para cobertura do déficit atuarial do regime de previdência dos servidores públicos (RPPS). Seguindo a portaria conjunta STN/SOF n²/2010, os gastos nesse item passaram a ser descontados do gasto total com pessoal. Caso esses gastos fossem considerados em 2011, por exemplo, a razão despesas com pessoal/RCL seria de $49,21 \%$ e não $38,85 \%$. Em 2018, esses gastos voltaram a ser considerados como despesa de pessoal. 
O mesmo vale para a relação entre a dívida consolidada líquida e a receita corrente líquida, que em 2016 superou o limite de $200 \%$.

A partir da série de dados disponíveis, agrupando-se os períodos em quadriênios, verifica-se que nos últimos anos o crescimento médio das receitas se reduziu pela metade. Inclusive, foi inferior à inflação média observada no período. Embora o crescimento médio das despesas tenha também diminuído, essa redução não foi suficiente para compensar a desaceleração da receita. ${ }^{12}$

Tabela 3 Crescimento médio da receita e despesa, média geométrica por quadriênio Minas Gerais - 2003-2018 - (\%)

\begin{tabular}{|c|c|c|c|c|c|}
\hline Especificação & $\begin{array}{r}2003-2006 \\
\text { (PSDB) }\end{array}$ & $\begin{array}{r}2007-2010 \\
\text { (PSDB) }\end{array}$ & $\begin{array}{r}2011-2014 \\
\text { (PSDB) }\end{array}$ & $\begin{array}{r}2015-2018 \\
(\mathrm{PT})\end{array}$ & $\begin{array}{r}\text { Média do } \\
\text { período } \\
(2003-2018)\end{array}$ \\
\hline Despesas & 10,65 & 12,24 & 13,16 & 8,07 & 11,01 \\
\hline Receitas & 11,96 & 12,50 & 12,00 & 5,76 & 10,52 \\
\hline Média da Inflação (IPCA) & 6,41 & 5,14 & 6,16 & 5,87 & 5,90 \\
\hline
\end{tabular}

Fonte: Elaboração própria a partir de dados do Siafi-MG.

Dessa forma, considera-se que, apesar do esforço fiscal dos últimos anos, a retração da atividade econômica, associada à dificuldade de conter o crescimento da despesa, resultou na piora sensível do quadro fiscal. Nesses termos, paradoxalmente, a gestão petista teria se mostrado mais responsável no controle das despesas do que as gestões anteriores, que estão mais à direita no espectro político.

Nas seções seguintes, com vistas a explorar essa hipótese, detalham-se tanto a estrutura quanto a trajetória das receitas e das despesas orçamentárias. Em particular, destacam-se os resultados referentes ao último quadriênio.

Dessa forma, a apuração desse indicador subiu bruscamente.

12 Alternativamente, estudos fiscais, tal qual o do Instituto de Pesquisa Econômica Aplicada (IPEA) de 2014, avaliam o crescimento da receita/despesa em proporção do PIB. Entretanto, tendo em vista a magnitude da crise do último quadriênio, optou-se por avaliar apenas a taxa de crescimento em termos nominais, comparando-a à inflação observada. Os cálculos em proporção do $\mathrm{PIB}$, inclusive, levam a interpretações diferentes, caso não se utilize medidas alternativas para o último quadriênio (e.g., PIB "tendencial"). 


\section{Dinâmica das receitas orçamentárias}

A estrutura das receitas orçamentárias variou muito pouco ao longo dos anos, conforme retrata o Gráfico 1. Importante esclarecer que as receitas são agrupadas em receitas correntes, que são compostas pelas receitas tributárias, de contribuições, patrimonial, industrial, de serviços e ainda as provenientes de outras pessoas de direito público ou privado (transferências correntes); e em receitas de capital, que se subdividem em operações de empréstimos, alienação de bens, transferências de capital, amortizações de empréstimos e outras receitas de capital. As receitas tributárias somadas às transferências correntes correspondem a mais de $70 \%$ do total desde 2002.

Gráfico 1 Estrutura das receitas - Minas Gerais - 2002-2018 - (\%)

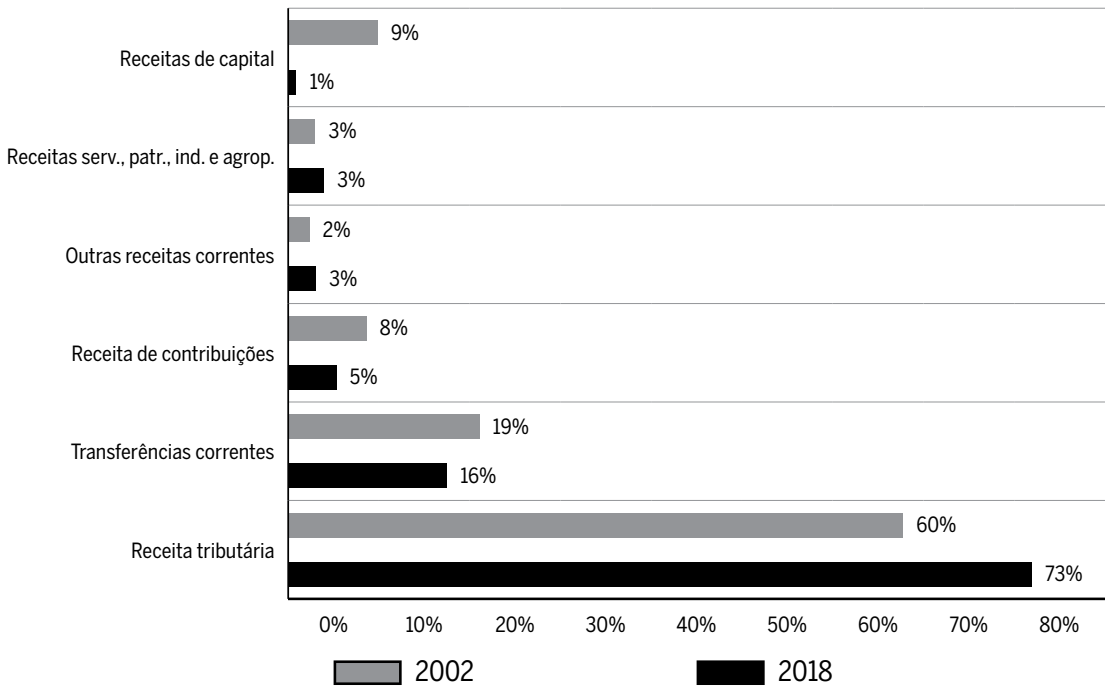

Fonte: Elaboração própria com base nos dados do SIAFI-MG.

Nota: Não foram consideradas as receitas intraorçamentárias em 2018, pois essa classificação não existia em 2002.

Apesar de certas diferenças, ${ }^{13}$ em linhas gerais, a estrutura orçamentária

13 As diferenças mais marcantes entre a estrutura da receita de 2002 vis-à-vis à de 2018 são: a) a queda da participação da receita das contribuições e b) a diminuição significativa das receitas de capital. 
da receita foi bastante regular ${ }^{14}$ ao longo dos últimos 16 anos. Logo, é importante entender a dinâmica das principais receitas, a fim de explicar sua desaceleração.

De acordo com Pires (2017), o primeiro fato estilizado dos ciclos fiscais, em nível nacional, é o fato de a taxa de crescimento das receitas tributárias acompanharem a atividade econômica em razão superior a um. Em outras palavras, quando a atividade econômica se acelera (desacelera), as receitas tributárias crescem (decrescem) mais do que proporcionalmente.

No caso particular dos estados, não necessariamente se identifica esse padrão. Conforme o Gráfico 2, existem períodos em que ela cai mais do que o PIB e outros em que o reverso ocorre. Isto é, o crescimento da receita deveria estar acima (abaixo) do crescimento do PIB quando ele se acelera (desacelera).

Usualmente, em momentos de crise econômica, os governos implementam diversas medidas para aumentar as arrecadações. Logo, no caso mineiro, recessões (expansões) econômicas nem sempre foram acompanhadas de retrações (crescimento) das receitas tributárias mais do que proporcionais à queda da atividade.

\section{Gráfico 2 Taxa de crescimento da receita tributária e PIB nominal - Minas Gerais - 2003-2018-(\%)}

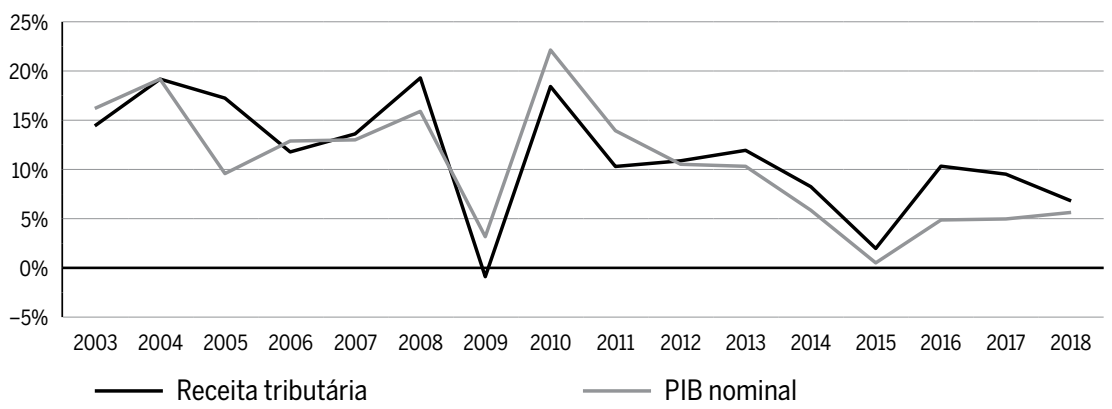

Fonte: Elaboração própria a partir de dados do Siafi-MG.

Nota: O PIB nominal para o $4^{\circ}$ trimestre 2018 foi previsto utilizando-se uma regressão linear com um termo de tendência e variáveis dummy para capturar as sazonalidades trimestrais.

14 À exceção das receitas oriundas de operações de crédito, que em 2012 e 2013 cresceram acima de $5 \%$ ao ano. 
A Tabela 4, assim como o Gráfico 2, mostra que, no período recente, $2015^{15}$ a 2018 , o crescimento de todas as principais fontes de receita se desacelerou intensamente (embora tenha sido superior à variação do PIB nominal). Existe um vínculo muito forte entre a obtenção dessas receitas e o desempenho econômico estadual e do país, na medida em que elas estão vinculadas à produção e à circulação de bens e serviços. Em particular, parcela considerável (próximo a 80\%) das receitas tributárias estaduais depende do Imposto sobre Circulação de Mercadorias e Serviços (ICMS).

Tabela 4 Crescimento da Receita Efetivada, principais subcategorias, média geométrica por quadriênio - 2003-2018 - (\%)

\begin{tabular}{l|r|r|r|r|r}
\hline Especificação & $\begin{array}{r}\mathbf{2 0 0 3 - 2 0 0 6} \\
\text { (PSDB) }\end{array}$ & $\begin{array}{r}\mathbf{2 0 0 7 - 2 0 1 0} \\
\text { (PSDB) }\end{array}$ & $\begin{array}{r}\mathbf{2 0 1 1 - 2 0 1 4} \\
\text { (PSDB) }\end{array}$ & $\begin{array}{r}\mathbf{2 0 1 5 - 2 0 1 8} \\
\text { (PT) }\end{array}$ & $\begin{array}{r}\text { Média do } \\
\text { período } \\
\text { (2003-2018) }\end{array}$ \\
\hline Receita tributária & 15,64 & 12,32 & 10,35 & 7,12 & 11,32 \\
\hline Transferências correntes & 12,99 & 15,33 & 7,22 & $-1,39$ & 8,34 \\
\hline Receita total & 11,96 & 12,50 & 12,00 & 5,76 & 10,52 \\
\hline Inflação (IPCA) & 6,41 & 5,14 & 6,16 & 5,87 & 5,90 \\
\hline PIB-MG real & 3,98 & 3,73 & 1,38 & $-0,83$ & 2,04 \\
\hline
\end{tabular}

Fonte: Elaboração própria a partir de dados do Siafi-MG e da Fundação João Pinheiro (FJP)-MG.

Nota: Para o PIB-MG real para 2018 foi considerada a taxa de variação acumulada nos últimos quatro trimestres terminados em setembro de 2018 (em relação ao mesmo período do ano anterior).

Em que pese a drástica redução tanto das receitas tributárias e especialmente das transferências correntes, deve-se destacar que houve um esforço de aumento de arrecadação estadual, bastante visível desde 2012, na gestão psdbista, e mais pronunciada no último quadriênio. Depreende-se, então, que a busca de novas receitas e de aumento de arrecadação não parece depender da orientação política e sim do quadro econômico e fiscal. Apresentam-se, na sequência, breves considerações em relação ao desempenho da receita no último quadriênio.

15 A Portaria Interministerial STN/SOF $n^{\circ}$ 5, de 25 de agosto de 2015, alterou a estrutura de códigos da classificação da receita quanto à natureza. A nova estrutura foi adotada pelo estado de Minas Gerais a partir do exercício financeiro de 2018. Na nova codificação, os valores de multas e juros de mora, dívida ativa, e multas e juros de mora da dívida ativa referente a impostos e taxas são classificados como Receita Tributária. Como até 2017 esses valores eram classificados como Outras Receitas Correntes, nas tabelas e gráficos apresentados neste artigo, para comparabilidade da série temporal da Receita Tributária, todos os anos apresentam somente o valor principal de impostos e taxas. 


\subsection{Dinâmica das receitas orçamentárias - 2015-2018}

Nesse período, a receita tributária apresentou resultados positivos mesmo quando o PIB variou negativamente, e, quando o PIB voltou a crescer em 2017, a elasticidade da receita em relação ao PIB nominal foi superior a um. Esse desempenho favorável foi alcançado a partir de medidas de curto prazo. Entre elas, menciona-se o aumento do ICMS sobre diversos produtos considerados supérfluos, tais como ração tipo pet, perfumes e cosméticos etc. (Lei no 21.781, de 01 de outubro de 2015).

Ainda, em 2015, ingressaram nos cofres públicos R $\$ 4,8$ bilhões referentes aos depósitos judiciais, conforme a Lei no 21.720/15, que dispõe sobre a utilização desses recursos. Porém, essa receita foi contabilizada na subcategoria outras receitas correntes apenas nesse ano. ${ }^{16}$

Em 2016, houve a entrada de recursos extraordinários da ordem de R \$ 1,3 bilhão decorrente da cessão do direito de operacionalização da fotha de pagamento do servidor ao Banco do Brasil. Essa receita foi classificada na subcategoria "receitas patrimoniais". Nesse mesmo ano, a União repassou ao estado R \$ 363 milhões relativos ao Programa de Regularização de Ativos no Exterior. Dessa forma, nesse ano, apesar da queda de 1,8\% do PIB, o aumento de alíquota de ICMS no final de 2015 e outras receitas extraordinárias impulsionaram a arrecadação tributária.

Tabela 5 Crescimento da Receita Efetivada, principais subcategorias - 2015-2018 - (\%)

\begin{tabular}{lrr|r|r|r|r}
\hline Especificação & $\mathbf{2 0 1 5}$ & $\mathbf{2 0 1 6}$ & $\mathbf{2 0 1 7}$ & $\mathbf{2 0 1 8}$ & $\begin{array}{r}\text { Média do } \\
\text { quadriênio } \\
\mathbf{2 0 1 5 - 2 0 1 8 )}\end{array}$ & $\begin{array}{r}\text { Média do } \\
\text { período } \\
\mathbf{( 2 0 0 3 - 2 0 1 8 )}\end{array}$ \\
\hline Receita tributária & 1,98 & 10,35 & 9,53 & 6,81 & 7,12 & 11,32 \\
\hline Transferências correntes & $-0,84$ & 10,21 & $-1,40$ & $-12,24$ & $-1,39$ & 8,34 \\
\hline Receita total & 3,83 & 10,26 & 5,55 & 3,53 & 5,76 & 10,52 \\
\hline Inflação (IPCA) & 10,67 & 6,29 & 2,95 & 3,75 & 5,87 & 5,90 \\
\hline PIB-MG real & $-4,26$ & $-2,02$ & 1,38 & 1,70 & $-0,83$ & 2,04 \\
\hline
\end{tabular}

Fonte: Elaboração própria a partir de dados do SIAFI-MG, PIB Trimestral $3^{\circ}$ Trimestre 2018/FJP e Instituto Brasileiro de Geografia e Estatística (IBGE).

Nota: Para o PIB-MG real para 2018 foi considerada a taxa de variação acumulada nos últimos quatro trimestres terminados em setembro de 2018 (em relação ao mesmo período do ano anterior).

16 O repasse dos depósitos judiciais foi suspenso em razão da Ação Direta de Inconstitucionalidade (ADIN) $n^{\circ} 5.353$. 
Em 2017 e 2018, o crescimento de arrecadação das receitas tributárias, comparado ao ano imediatamente anterior, se desacelerou (Tabela 5). À medida que foram se esgotando fontes alternativas de receita, o desempenho foi piorando. No cômputo geral, o crescimento médio da arrecadação foi inferior à inflação.

Admite-se, também, que o desempenho da arrecadação não se deve somente ao aumento da tributação e ao ingresso de receitas não recorrentes. Medidas de gestão, tal qual o programa estadual de eficiência fiscal (Decreto no $47.116 / 2016$ ), devem ter contribuído para a performance observada.

Destaca-se, por último, que o desempenho das transferências correntes foi bem inferior ao das receitas tributárias. ${ }^{17} \mathrm{~A}$ base de impostos que compõe essa subcategoria de receita é mais diversa, ao passo que a receita tributária depende basicamente do ICMS, que é mais correlacionado à atividade econômica.

Em linhas gerais, neste estudo, importa realçar que os esforços de arrecadação não são explicados pela mudança de orientação política. Embora o desempenho da arrecadação tenha sido particularmente favorável no último quadriênio, desde 2012 a performance da receita tributária tem sido melhor do que a do PIB nominal. Portanto, infere-se que quando os governantes encontram dificuldades para fechar as contas eles adotam medidas para aumentar a arrecadação.

\section{Dinâmica das despesas orçamentárias}

A estrutura das despesas orçamentárias, assim como a das receitas, é bastante constante ao longo dos anos. ${ }^{18}$ Primeiro, é importante esclarecer que as despesas são classificadas de acordo com a categoria econômica: corren-

17 O resultado para as transferências em 2018, muito abaixo em relação a 2017, é, sobretudo, decorrente da diminuição das transferências de recursos do Fundo de Manutenção e Desenvolvimento da Educação Básica e de Valorização dos Profissionais da Educação (Fundeb) recebidos pelo Estado. No entanto, essa diminuição ocorreu em grande medida pela retenção, por parte do próprio Estado, da parcela de sua arrecadação vinculada ao Fundeb.

18 No Gráfico 3, Estrutura das despesas de 2018, não incluímos as despesas intraorçamentária, que também passaram a ser discriminadas a partir de 2009. No grupo de natureza outras despesas correntes, a maior parcela das despesas intraorçamentária se refere aos aportes para cobertura do déficit atual do regime do servidor público (RPPS) e às contribuições do Fundo Estadual de Saúde (FES) decorrentes da Lei Complementar no 141 de 2012 (que regulamenta os valores mínimos a serem aplicados em saúde). As obrigações patronais do pessoal ativo e inativo são a principal despesa do grupo pessoal e encargos sociais. 
tes e de investimento. Adicionalmente, elas são agrupadas de acordo com o grupo de natureza, que corresponde à agregação de elementos de despesa que apresentam as mesmas características quanto ao objeto do gasto (e.g., todos os gastos com vencimentos, gratificações, abonos etc. estão no elemento vencimentos e vantagens fixas - pessoal civil). Existe, ainda, o item de despesa, que é um detalhamento dos elementos de despesa (e.g., vencimentos, adicional de desempenho etc.).

As despesas correntes correspondem, aproximadamente, a 90\% do total, sendo que a maior parte se refere aos gastos com pessoal e encargos sociais e a outras despesas correntes (Gráfico 3). Ainda que as despesas de investimento representem fração pequena da despesa total, ela constitui a principal variável de ajuste fiscal (Pires, 2017). Assim, é importante analisar seu comportamento. ${ }^{19}$

Gráfico 3 Estrutura das despesas - Minas Gerais - 2002-2018 - (\%)

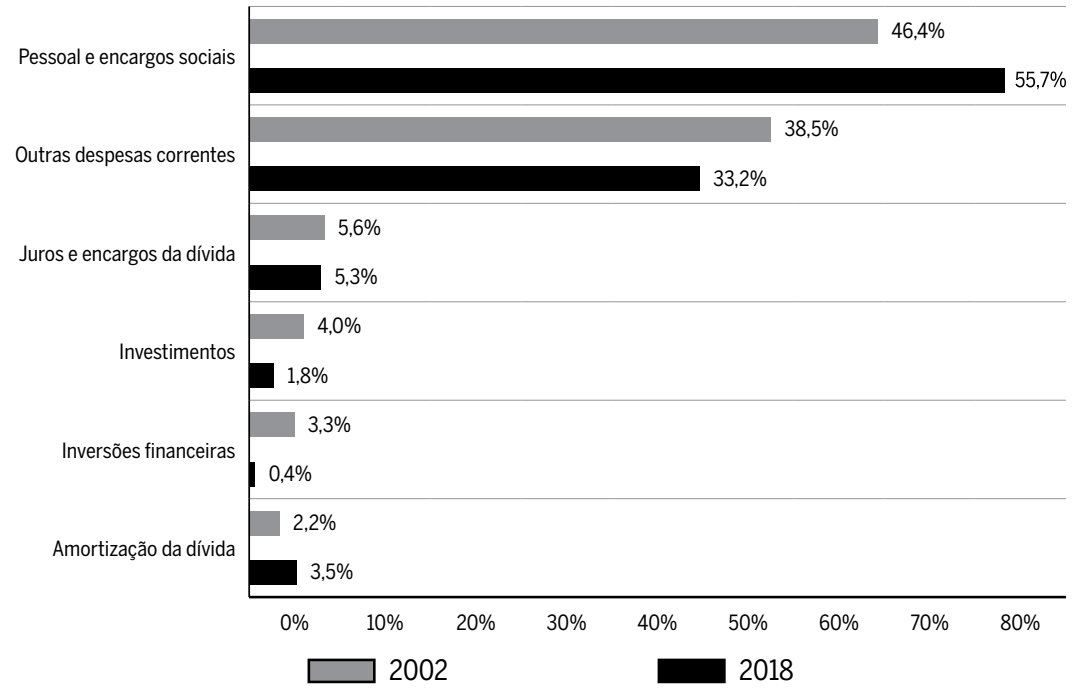

Fonte: Elaboração própria a partir de dados do Siafi-MG.

Nota: Os dados não consideram as receitas intraorçamentárias.

De fato, nota-se que, à exceção das despesas de capital, inclusive investimentos, as demais despesas mantiveram-se mais próximas à média históri19 Ocioso notar que dada sua pequena magnitude, a oscilação da média dos gastos é muito maior. 
ca, de acordo com a Tabela 6. Ou seja, cresceram, em média, acima da inflação. Em particular, observa-se que os gastos com pessoal e encargos sociais foram crescentes ao longo dos anos, sendo que apenas no último quadriênio houve redução na velocidade do crescimento. Logo, embora a orientação do governo do PT seja mais à esquerda, sua política de pessoal tem priorizado a contenção dos gastos nessa área, inclusive por limitações legais da LRF.

Tabela 6 Crescimento da despesa orçamentária por principais grupos de natureza, média geométrica por quadriênio - 2003-2018 - (\%)

\begin{tabular}{l|r|r|r|r|r}
\hline Especificação & $\begin{array}{r}\text { 2003-2006 } \\
\text { (PSDB) }\end{array}$ & $\begin{array}{r}\text { 2007-2010 } \\
\text { (PSDB) }\end{array}$ & $\begin{array}{r}\text { 2011-2014 } \\
\text { (PSDB) }\end{array}$ & $\begin{array}{r}\text { 2015-2018 } \\
\text { (PT) }\end{array}$ & $\begin{array}{r}\text { Média do } \\
\text { período } \\
\text { (2003-2018) }\end{array}$ \\
\hline Despesas de capital & 20,61 & 11,56 & 8,84 & $-13,04$ & 6,23 \\
\hline Investimentos & 36,76 & 10,15 & 1,08 & $-22,11$ & 4,36 \\
\hline Despesas correntes & 9,42 & 12,34 & 13,78 & 10,01 & 11,37 \\
\hline Outras despesas correntes & 8,69 & 13,21 & 12,71 & 10,98 & 11,38 \\
\hline Pessoal e encargos sociais & 9,23 & 12,74 & 15,36 & 9,08 & 11,57 \\
\hline Total geral & 10,65 & 12,24 & 13,16 & 8,07 & 11,01 \\
\hline Inflação (IPCA) & 6,41 & 5,14 & 6,16 & 5,87 & 5,90 \\
\hline
\end{tabular}

Fonte: Elaboração própria a partir de dados do SIAFI-MG e IBGE.

Portanto, analisa-se, a seguir, o comportamento das despesas no último quadriênio, em particular dos gastos com investimento e com pessoal e encargos sociais.

\subsection{Dinâmica das despesas orçamentárias - 2015-2018}

\section{Despesas com pessoal}

Em 2015, o crescimento dos gastos com despesas correntes foi puxado pelos gastos com pessoal e encargos sociais. Existem duas explicações para esse crescimento. A primeira é o próprio crescimento vegetativo da folha. A segunda são os reajustes escalonados de salários e vencimentos de várias carreiras, aprovados entre 2011 e 2014 na gestão do governador Antônio Anastasia (Leis 19.576, de 16/08/11; 20.748, de 25/06/13; 21.216, de 07/05/14; 21.167, de 17/01/14 etc.). Nota-se que, em contraposição ao 
observado em 2015, o ritmo de crescimento se desacelerou de $2016^{20} \mathrm{em}$ diante (vide Tabela 8).

\section{Despesas com encargos da dívida}

Em 2016, a renegociação da dívida dos estados com a União (a maior parcela da dívida estadual é com a União), materializada na Lei Complementar no 156, de 28 de dezembro de 2016, reduziu os gastos com despesas de juros e encargos sociais em quase $\mathrm{R} \$ 2$ bilhões. Esse fator contribuiu decisivamente para a queda de mais de 4 pontos percentuais, em relação à média histórica, na taxa de crescimento das despesas correntes em 2016.

\section{Gastos com outras despesas correntes}

O ritmo de crescimento dos gastos com outras despesas correntes não acompanhou a queda da inflação. Os aportes para a cobertura do déficit atuarial do RPPS, que vem crescendo a taxas superiores a $30 \%$, contribuíram decisivamente para o comportamento dessa categoria de despesa (em 2018, cerca de R 10 bilhões foram gastos nesse item, representando cerca de $1 / 4$ do total). Assim, os gastos previdenciários se conformam como um problema estrutural (vide Tabela 7), que perpassam administrações de diferentes matizes ideológicos, ainda sem solução.

No entanto, em 2018, o crescimento do déficit da previdência desacelerou substancialmente. Adicionalmente, em virtude da crise fiscal, houve queda no custeio da máquina pública.

Tabela 7 Resultado previdenciário - Minas Gerais - 2007-2018 - (em milhões $\mathrm{R} \$ 1,00$ )

\begin{tabular}{lrr|r}
\hline Ano & $\begin{array}{r}\text { Despesas } \\
\text { previdenciárias }\end{array}$ & $\begin{array}{r}\text { Receitas } \\
\text { previdenciárias }\end{array}$ & $\begin{array}{r}\text { Resultado } \\
\text { previdenciário }\end{array}$ \\
\hline $\mathbf{2 0 0 7}$ & $6.118,10$ & $2.099,08$ & $(4.019,02)$ \\
\hline $\mathbf{2 0 0 8}$ & $6.923,16$ & $2.269,55$ & $(4.653,61)$ \\
\hline $\mathbf{2 0 0 9}$ & $7.218,59$ & $2.401,83$ & (4.816,76) \\
\hline
\end{tabular}

$20 \mathrm{Na}$ gestão do governador Fernando Pimentel, houve reajuste dos salários dos servidores da educação (Lei no 21.710, 21/04/16). Ou seja, seu efeito se deu em 2016. 
Tabela 7 (continuação)

\begin{tabular}{lrr|r}
\hline Ano & $\begin{array}{r}\text { Despesas } \\
\text { previdenciárias }\end{array}$ & $\begin{array}{r}\text { Receitas } \\
\text { previdenciárias }\end{array}$ & $\begin{array}{r}\text { Resultado } \\
\text { previdenciário }\end{array}$ \\
\hline $\mathbf{2 0 1 0}$ & $8.782,43$ & $2.669,37$ & $(6.113,06)$ \\
\hline $\mathbf{2 0 1 1}$ & $9.941,34$ & $3.121,39$ & $(6.819,95)$ \\
\hline $\mathbf{2 0 1 2}$ & $11.388,78$ & $4.622,96$ & $(6.765,81)$ \\
\hline $\mathbf{2 0 1 3}$ & $12.678,92$ & $4.361,74$ & $(8.317,18)$ \\
\hline $\mathbf{2 0 1 4}$ & $14.720,89$ & $5.370,35$ & $(9.350,54)$ \\
\hline $\mathbf{2 0 1 5}$ & $18.441,78$ & $9.591,26$ & $(8.850,52)$ \\
\hline $\mathbf{2 0 1 6}$ & $20.290,60$ & $5.429,92$ & $(14.860,68)$ \\
\hline $\mathbf{2 0 1 7}$ & $22.030,92$ & $5.553,41$ & $(16.477,52)$ \\
\hline $\mathbf{2 0 1 8}$ & $23.238,23$ & $5.948,42$ & $(17.289,81)$ \\
\hline
\end{tabular}

Fonte: Elaboração própria a partir de dados da SEF (2002-2018).

Nota: Anteriormente ao exercício de 2018, o resultado previdenciário era divulgado no critério da despesa liquidada, distinto do critério da despesa empenhada demonstrado para os anos de 2007 a 2018.

\section{Despesas de capital}

$\mathrm{Na}$ outra ponta, a contenção das despesas de capital foi a mais acentuada. No total, considerando os gastos com amortizações, inversões financeiras e investimento, a variação média foi negativa em $13 \%$ no último quadriênio.

A queda dos gastos com amortizações se explica em função da renegociação das dívidas estaduais com a União e com o Banco Nacional de Desenvolvimento Econômico e Social (BNDES). As inversões financeiras se referem, grosso modo, a despesas orçamentárias com a aquisição de imóveis ou bens de capital já em utilização e aquisição de títulos representativos do capital de empresas ou entidades de qualquer espécie já constituídas. Elas também decresceram.

Além disso, mais relevante do que a retração desses gastos foi a queda dos investimentos. Tais despesas são tidas como a principal variável de política fiscal para administrar o ciclo econômico. Os multiplicadores fiscais associados ao investimento são superiores a um, sobretudo quando existe elevada capacidade ociosa (Orair; Siqueira, 2016). Isso quer dizer que gastos de investimento costumam gerar crescimento mais do que proporcional ao montante dispendido. 
Tabela 8 Crescimento da despesa orçamentária por grupo de natureza, principais grupos de natureza - 2015-2018 - (\%)

\begin{tabular}{lrrrr|r|r|r}
\hline Especificação & $\mathbf{2 0 1 5}$ & $\mathbf{2 0 1 6}$ & $\mathbf{2 0 1 7}$ & $\mathbf{2 0 1 8}$ & $\begin{array}{r}\text { Média do } \\
\text { quadriênio } \\
\mathbf{( 2 0 1 5 - 2 0 1 8 )}\end{array}$ & $\begin{array}{r}\text { Média do } \\
\text { período } \\
\mathbf{( 2 0 0 3 - 2 0 1 8 )}\end{array}$ \\
\hline Despesas de capital & $-16,58$ & $-35,60$ & 17,13 & $-9,11$ & $-13,04$ & 6,23 \\
\hline Investimentos & $-23,55$ & $-13,09$ & 18,66 & $-53,31$ & $-22,11$ & 4,36 \\
\hline Despesas correntes & 16,45 & 7,11 & 11,34 & 5,47 & 10,01 & 11,37 \\
\hline Outras despesas correntes & 13,30 & 12,72 & 13,98 & 4,21 & 10,98 & 11,38 \\
\hline $\begin{array}{l}\text { Pessoal e encargos } \\
\text { sociais }\end{array}$ & 18,82 & 8,03 & 6,66 & 3,39 & 9,08 & 11,57 \\
\hline Total geral & 12,72 & 3,54 & 11,64 & 4,67 & 8,07 & 11,01 \\
\hline Inflação (IPCA) & 10,67 & 6,29 & 2,95 & 3,75 & 5,87 & 5,90 \\
\hline
\end{tabular}

Fonte: Elaboração própria a partir de dados do SIAFI-MG e IBGE.

Contudo, a maior parte das despesas não é discricionária. ${ }^{21}$ Dessa forma, usualmente, em épocas de crise econômica e fiscal, as despesas com investimentos são contingenciadas. Esse fato é confirmado no caso mineiro, demonstrado no Gráfico 4.

Gráfico 4 Evolução receitas vs. investimentos - Minas Gerais - 2002-2018 - (2002=100)

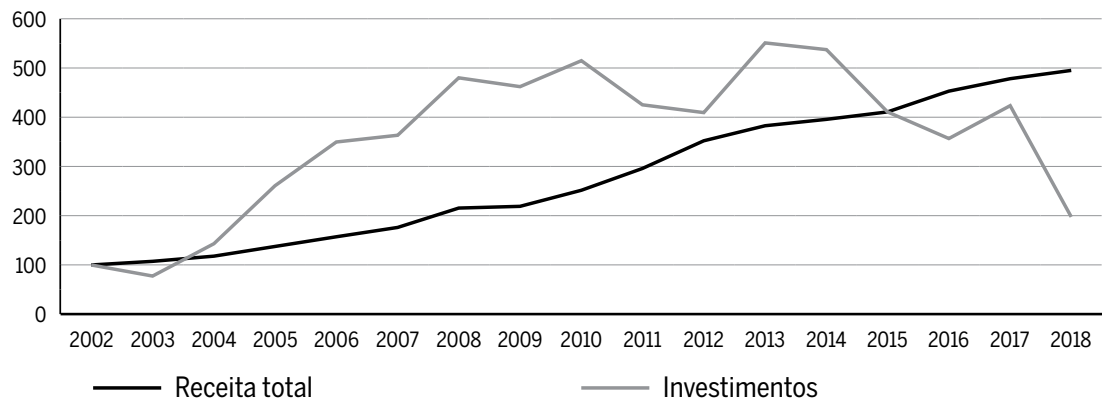

Fonte: Elaboração própria a partir de dados do SIAFI-MG.

21 De acordo com a Lei de Diretrizes Orçamentárias (LDO), a base contingenciável corresponde ao total das dotações estabelecidas na lei orçamentária de 2018, excluídas: as vinculações constitucionais; as obrigações legais; as despesas com o pagamento de precatórios e sentenças judiciais; as despesas com pessoal e encargos sociais; as despesas com juros e encargos da dívida; as despesas com amortização da dívida; as despesas com auxílio-doença, auxílio-funeral, auxílio-alimentação, auxílio-transporte e auxílio-fardamento financiados com recursos ordinários; as despesas com o Programa de Formação do Patrimônio do Servidor Público (Pasep). 
Depois de dois anos de queda consecutiva, houve crescimento, em 2017, de cerca de $18 \%$, sendo que, em termos nominais, o valor observado é ligeiramente superior ao de 2015. No entanto, em 2018, o investimento caiu pela metade. Observa-se que o aumento dos gastos de investimentos em ano pré-eleitoral é compatível com a tese de ciclos políticos orçamentários, pois eles seriam concluídos e inaugurados no ano eleitoral.

De qualquer modo, os gastos com investimento ainda estão longe do patamar pré-crise. Em última instância, essa desaceleração dos investimentos estaduais pode estar contribuindo para a recuperação lenta da atividade econômica.

Em linhas gerais, do ponto de vista da despesa, a gestão petista se mostrou mais responsável do que a última gestão do PSDB, principalmente em virtude das restrições legais (LRF) e do aprofundamento da crise econômica. $O$ crescimento da despesa dos principais grupos se desacelerou.

\section{Considerações finais}

A trajetória dos indicadores fiscais do estado de Minas Gerais sugere visível incompatibilidade entre a teoria e os resultados empíricos. Se, teoricamente, governos mais à esquerda seriam mais propensões à liberalização dos gastos, parece que, na prática, ocorreu o inverso. Ou seja, a velocidade de crescimento dos gastos foi crescente ao longo dos governos do PSDB e só se desacelerou no governo do PT.

No entanto, mesmo com a desaceleração de gastos com pessoal e com investimentos, foram registrados sucessivos déficits fiscais no último quadriênio. Em particular, em termos nominais, o déficit orçamentário de 2018, superior a 10 bilhões, foi o mais alto desde o início da série histórica.

Por um lado, questões conjunturais foram decisivas para a manifestação da crise fiscal. A queda acumulada de $6,1 \%$ da atividade econômica no biênio 2015-2016 provocou a desaceleração das receitas. Desse modo, o crescimento médio das receitas no último quadriênio foi inferior à inflação média observada no mesmo período. Ou seja, houve queda em termos reais, apesar de o desempenho da arrecadação ter surpreendido positivamente.

Por outro lado, existem questões estruturais que dificultam o ajuste fiscal. Via de regra, o crescimento das despesas é bastante superior ao da in- 
flação. Embora o ritmo de crescimento, em termos reais, tenha diminuído no último quadriênio, os resultados orçamentários se deterioraram.

Pesa desfavoravelmente nessa equação a rigidez dos gastos públicos. Os gastos com pessoal, amortização e juros da dívida representaram, em 2018, mais de 50\% das despesas. Adicionalmente, os governos estaduais devem cumprir os gastos mínimos constitucionais na educação, saúde, ciência tecnologia, etc. Soma-se, ainda, no caso mineiro, o crescente gasto com a cobertura dos déficits do regime de previdência do RPPS, equivalente a aproximadamente $10 \%$ dos gastos totais nesse mesmo ano. Portanto, a margem de manobra do governo estadual é baixa.

Nesse cenário, ganha força a tese de que as restrições legais têm desempenhado um papel duplo: conformaram, de forma pró-cíclica, os gastos do estado ao mesmo tempo que enfraqueceram seu papel na federação. Assim, as contas públicas de muitos estados, em especial de Minas Gerais, se encontram em situações de calamidade financeira. As duas respostas possíveis, nesse caso, seriam: endurecer mais as regras dos gastos públicos estaduais ou reavaliar o papel dos estados na federação. O primeiro remédio, ao invés de socorrer, pode matar o paciente. $O$ segundo é um tema bastante espinhoso e requer coordenação política dos entes federados. Logo, não parecer ser uma solução de curto nem médio prazo. É provável, então, que o paciente continue agonizando até que o governo federal venha em seu socorro (a exemplo do estado do Rio de Janeiro).

\section{Referências}

ALESINA, A.; ROUBINI, N. Political Cycles in OECD Economies. National Bureau of Economic Research, Working Paper n. 3478, Cambridge, p. 1-40, Oct. 1990.

ALESINA, A.; ROUBINI, N.; COHEN, G. Political Cycles and the Macroeconomy. Cambridge, MA: MIT Press, 1997.

ARVATE, P. R.; AVELINO, G.; LUCINDA, C. R. Existe influência da ideologia sobre o resultado fiscal dos governos estaduais brasileiros? Estudos Econômicos, v. 38, n. 4, p. 789-814, 2008.

BITTENCOURT, J. L.; HILBRECHT, R. O. Ciclo político na economia brasileira: um teste para a execução orçamentária dos governos estaduais: 1983-2000. In: ENCONTRO DA ASSOCIAÇÃO NACIONAL DOS CENTROS DE PÓS-GRADUAÇÃO EM ECONO-

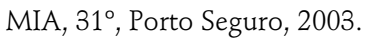

BOTELHO, F. Determinantes do ajuste fiscal dos Estados brasileiros. Dissertação (Mestrado) - Faculdade de Economia e Administração da Universidade de São Paulo, 2002. 
BRASIL. Portaria STN no 328, de 27 de agosto de 2001. Alterações no FUNDEF. Brasília, DF, ago. 2001.

BRASIL. Lei Complementar no 101, de 4 de maio de 2001. Estabelece normas de finanças públicas voltadas para a responsabilidade na gestão fiscal e dá outras providências. Brasília, DF, maio de 2001.

BRASIL. Portaria Intermininsterial no 338, de 26 de abril de 2006. Altera o Anexo I da Portaria Interministerial STN/SOF 163, de 4 de maio de 2001, e dá outras providências. Brasília, DF, abr. de 2006.

BRASIL. Lei Complementar no 156, de 28 de dezembro de 2016. Estabelece o Plano de Auxílio aos Estados e ao Distrito Federal e medidas de estímulo ao reequilíbrio fiscal; e altera a Lei Complementar no 148, de 25 de novembro de 2014, a Lei no 9.496, de 11 de setembro de 1997, a Medida Provisória no 2.192-70, de 24 de agosto de 2001, a Lei no 8.727, de 5 de novembro de 1993, e a Lei Complementar no 101, de 4 de maio de 2000. Brasília, DF, dez. 2016.

BRENDEN, A.; DRAZEN, A. Political Budget Cycles in New Versus Established Democracies. Journal of Monetary Economics, v. 52, n. 7, p. 1271-1295, 2005.

CHEVITARESE, N. H. Gastos públicos em Minas Gerais: o engessamento do orçamento e as prioridades dos governos no período 1999 a 2006. Dissertação (mestrado) - Escola de Governo da Fundação João Pinheiro, 2009.

COLOMBO, J. A.; LAZZARI, M. R. Timing, duração e magnitude da recessão econômica de 2014-2016 nos estados brasileiros. In: ENCONTRO DA ASSOCIAÇÃO NACIONAL DOS CENTROS DE PÓS-GRADUAÇÃO EM ECONOMIA, 46º, Rio de Janeiro, 2018.

CONNOLLY, J. M.; MASON, D. P. Ideology and Local Public Expenditure Priorities. Political Research Quarterly, v. 69, n. 4, p. 830-841, 2016.

COSSIO, F. A. B. Comportamento fiscal dos governos estaduais brasileiros: determinantes políticos e efeitos sobre o bem-estar dos seus Estados. Prêmio Tesouro Nacional. 2001.

COVRE, J.; DE MATTOS, L. B. A situação fiscal e os ciclos políticos nos municípios brasileiros: uma analise a partir de dados em painel dinâmico espacial. IN: ENCONTRO DA ASSOCIAÇÃO NACIONAL DOS CENTROS DE PÓS-GRADUAÇÃO EM ECONOMIA,

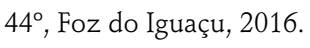

DASH, B. B.; RAJA, A. V. Political Determinants of the Allocation of Public Expenditures: A Study of the Indian States. National Institute of Public Finance and Policy, Working Papers 12/101, 2012.

DOWNS, A. An Economic Theory of Democracy. New York: Harper Collins Publishers, 1957.

FUNDAÇÃO JOÃO PINHEIRO (FJP). Produto Interno Bruto de Minas Gerais: Referência 2016. Belo Horizonte, 2018 (Série Estatística \& Informações n. 16).

FUNDAÇÃO JOÃO PINHEIRO (FJP). Relatório Metodológico do PIB Trimestral de Minas Gerais: Referência 2010. Belo Horizonte, 2017 (Série Estatística \& Informações n. 2).

HIBBS, D. A. Political Parties and Macroeconomic Policy. American Political Science Review, v. 71, n. 4, p. 1467-1487, 1977.

INSTITUTO FISCAL INDEPENDENTE (IFI). Observatório das Finanças Públicas Estaduais. Estudo Especial, n. 8, dez. 2018. 
INSTITUTO DE PESQUISAS ECONÔMICAS APLICADAS (IPEA). Finanças públicas e macroeconomia no Brasil: um registro da reflexão do IPEA (2008-2014), v.1, 2, 2014.

INSTITUTO DE PESQUISAS ECONÔMICAS APLICADAS (IPEA). Carta de Conjuntura: Finanças Públicas Estaduais, 39, 2o trimestre, 2018.

JAYME JR., F. G.; REIS, J. C.; ROMERO, J. P. Restrição orçamentária e Lei de Responsabilidade Fiscal: um estudo para Minas Gerais - 1995-2006. Ensaios FEE, v. 28, n. 2, p. 409-442, 2007.

KICKERT, W. J. M.; RANDMA-LIIV, T.; SAVI, R. Politics of Fiscal Consolidation in Europe: A Comparative Analysis. International Review of Administrative Sciences, v. 81, n. 3, p. 562 584, Sept. 2015.

LEAL FILHO, R. S.; L. O. S. BARBOSA. O impacto da crise econômica nas finanças públicas estaduais: o caso de Minas Gerais. Brazilian Keynesian Review, v. 4, n. 1, p. 116-132, $1^{\circ}$ sem. 2018.

LOPREATO, F. L. C. Finanças estaduais: alguns avanços, mas... (os exemplos de São Paulo, Rio de Janeiro e Rio Grande do Sul). Texto para Discussão, IE/UNICAMP, n. 145, jul. 2008.

MINAS GERAIS. Lei ${ }^{\circ} 20.748$, de 25 de junho de 2013. Reajusta as tabelas de vencimento básico das carreiras que menciona, institui a gratificação complementar no âmbito da Escola de Saúde Pública do estado de Minas Gerais - ESP-MG -, institui a carreira de auditor assistencial estadual do sistema único de saúde no estado e dá outras providências, Belo Horizonte, MG, jun. 2013.

MINAS GERAIS, Lei n ${ }^{\circ} 21.216$, de 07 de maio de 2014. Fixa o subsídio dos membros da defensoria pública do estado, Belo Horizonte, MG, jun. 2013.

MINAS GERAIS, Lei n 21.167, de 17 de janeiro de 2014. Incorpora a gratificação complementar ao vencimento básico dos servidores das carreiras que menciona, cria cargos de provimento efetivo da carreira de analista de hematologia e hemoterapia, a que se refere a Lei $\mathrm{n}^{\circ} 15.462$, de 13 de janeiro de 2005 , institui regime de remuneração por subsídio para a carreira de professor de arte e restauro e dá outras providências, Belo Horizonte, MG, jan. 2014.

MINAS GERAIS, Lei n 21.170, de 30 de junho de 2016. Dispõe sobre a política remuneratória das carreiras do Grupo de Atividades de Educação Básica do Poder Executivo, altera a estrutura da carreira de Professor de Educação Básica e dá outras providências, Belo Horizonte, MG, jun. 2016.

MINAS GERAIS, Decreto $n^{\circ}$ 47.116, de dezembro de 2016. Institui o Programa Estadual de Eficiência Fiscal - Receitas Tributárias e regulamenta, no âmbito da Secretaria de Estado de Fazenda, o disposto no art. 189 da Lei n²2.257, de 27 de julho de 2016, que estabelece a estrutura orgânica da administração pública do Poder Executivo e dá outras providências, Belo Horizonte, MG, dez. 2016.

MINAS GERAIS. Lei n 21.781, de 01 de outubro de 2015. Altera as Leis n's 6.763, de 26 de dezembro de 1975, 12.729, de 30 de dezembro de 1997, 14.937, de 23 de dezembro de 2003, e 19.976, de 27 de dezembro de 2011, e dá outra providência, Belo Horizonte, MG, out. 2017.

MINAS GERAIS, Lei n 21.720, de 14 de setembro de 2017. Dispõe sobre a utilização de depósitos judiciais em dinheiro, tributários e não tributários, realizados em processos 
vinculados ao Tribunal de Justiça do Estado de Minas Gerais - TJMG -, para o custeio da previdência social, o pagamento de precatórios e assistência judiciária e a amortização da dívida com a União, Belo Horizonte, MG, out. 2017.

MINAS GERAIS. Lei n 19.576, de 16 de agosto de 2011. Reajusta os valores das tabelas de vencimento básico das categorias que menciona, Belo Horizonte, MG, ago. 2017.

MINAS GERAIS. Lei $n^{\circ} 22.626$, de 28 de julho de 2018. Dispõe sobre as diretrizes para a elaboração e a execução da lei orçamentária para o exercício de 2018 e acrescenta artigo à Lei $n^{\circ} 22.254$, de 25 de julho de 2016. Belo Horizonte, MG, jul. 2018.

NAKAGUMA, M.Y.; BENDER, S. A emenda da reeleição e a Lei de Responsabilidade Fiscal: impactos sobre ciclos políticos e performance fiscal dos Estados (1986-2002). Revista de Economia Aplicada, v. 10, n. 3, p. 377-397, 2006.

NORDHAUS, W. The Political Business Cycle. Review of Economic Studies, v. 42, n. 2, p. 169190, 1975.

OLIVEIRA, F. A.; SIQUEIRA, W. B. (Org.). As muitas Minas: ensaios sobre a economia mineira. Belo Horizonte: Corecon: Real. v. 1, 2010. 284 p.

ORAIR, R.; SIQUEIRA, F. Investimento público no Brasil: trajetória recente e relações com o ciclo econômico e regime fiscal. Prêmio Tesouro Nacional, 2016.

POTRAFKE, N. Does Government Ideology Influence Budget Composition? Empirical Evidence form OECD Countries. Economics of Governance, v. 12, n. 2, p. 101-134, 2011a.

POTRAFKE, N. Public Expenditures on Education and Cultural Affairs in the West German States: Does Government Ideology Influence the Budget Composition? German Economic Review, 12, p. 124-145, 2011 b.

PIRES, M. Política fiscal e ciclos econômicos: teoria e experiência recente. Rio de Janeiro, Elsevier: FGV, 2017.

QUEIROZ, M. C. L.; SILVA, A. B. Ciclos políticos orçamentários no estado do Ceará (19862006). Planejamento e Políticas Públicas, n. 35, p. 223-252, jul./dez. 2010.

SECRETARIA DE ESTADO DE FAZENDA (SEF). Relatório Resumido De Execução Orçamentária (RREO), $6^{\circ}$ bimestre, 2002-2018.

SCHUKNECHT, L. Fiscal Policy Cycles and Public Expenditure in Developing Countries. Public Choice, v. 102, n. 1-2, p. 115-130, 2000.

SHI, M.; SVENSSON, J. Political Budget Cycles: Do They Differ Across Countries and Why? Journal of Public Economics, v. 90, n. 8-9, p. 1367-1389, 2006.

SILVA, M. S. Teoria do federalismo fiscal: notas sobre as contribuições de Oastes, Musgrave, Shah e Ter-Minassian. Nova Economia, v. 15, n. 1, p. 117-137, 2005.

TUFTE, E. R. The Political Control of the Economy. Princeton: Princeton University Press, 1978.

VASCONCELOS, R. D.; FERREIRA JR., S.; NOGUEIRA JR., R. P. A dinâmica da execução orçamentária federal do Brasil sob a ótica dos ciclos políticos eleitorais, 1985-2010. Economia Aplicada, v. 17, n. 3, p. 325-354, 2013. 


\section{Sobre os autores}

Lúcio Otávio Seixas Barbosa - seixas.lucio@gmail.com Fundação João Pinheiro, Belo Horizonte, Minas Gerais, Brasil. ORCID: https://orcid.org/0000-0002-7949-1177.

Raimundo de Sousa Leal Filho - raimundo.sousa@fjp.mg.gov.br Fundação João Pinheiro, Belo Horizonte, Minas Gerais, Brasil.

ORCID: https://orcid.org/0000-0002-6526-5400.

Francisco Alves de Oliveira Junior - francisco.junior@cge.mg.gov.br Controladoria-Geral do Estado de Minas Gerais, Belo Horizonte, Minas Gerais, Brasil. ORCID: https://orcid.org/0000-0003-3390-0534.

Felipe Magno Parreiras de Sousa - felipe.sousa@planejamento.mg.gov.br Secretaria de Estado de Planejamento e Gestão, Belo Horizonte, Minas Gerais, Brasil. ORCID: https://orcid.org/0000-0001-7015-7044.

\section{Sobre 0 artigo}

Recebido em 10 de maio de 2018. Aprovado em 14 de março de 2019. 